\title{
V. Die thermale Entwässerung des Stilbit und Thaumasit; die Hydrate von Magnesium- und Kupfersulfat.
}

\author{
Von \\ H. F. Merwin in Washington. \\ (Übersetzt von K. Mieleitner in München.) \\ (Mit einer Textfigur.)
}

Beim Studium des Metahewettit wurde eine Entwässerungsmethode für Körper skizziert, deren Wasser nur bei hohen Temperaturen leicht ausgetrieben wird $\left.{ }^{1}\right)$. Diese Methode findet hier $A$ nwendung auf einen Teil des Wassers, das bei gewöhnlichen Temperaturen ohne Schwierigkeit weggeht. Etwa $0,5 \mathrm{~g}$ der Substanz wurden, so fein gepulvert, daß sie durch ein 40-60 maschiges Netz gesiebt werden konnten, in dünner Schicht zwischen zwei Reagenzgläschen gebracht, deren äußeres $1,5 \mathrm{~cm}$, das innere $1,0 \mathrm{~cm}$ breit war; letzleres war umgekehrt hineingesetzt, am geschlossenen Ende ausgezogen und mit einer kleinen Öflnung nach oben versehen. Das Ganze wurde bis fast zum oberen Ende in ein Ül- oder Nitratbad getaucht und auf der gewünschten Temperatur hinreichend lange erhalten; dann wurde gewogen. Der unmittelbare Zweck ist, das Verhältnis des Wasserverlustes bei stufenweise ansteigender Temperatur zu bestimmen. Knicke in der Kurve würden bestimmte Hydrate anzeigen, wenn solche existieren, vorausgesetzt, daß derartige Hydrate einen genügend großen Unterschied in ihren Dampfdrucken bei den Beobachtungstemperaturen besitzen. Solche charakteristische Knicke sind in der Figur dargestellt. In einer Richtung ist die Temperatur aufgetragen, in der anderen entweder die Zahl der Moleküle Wasser, die einem Molekül des wasserfreien Salzes entsprechen, oder der Gewichtsverlust in Prozenten. Die Kreise oder die Form der umgrenzten Flächen stellen den Entwässerungsgrad dar. Der Durchmesser eines Kreises

1) Hillebrand, Merwin und Wright, diese Zeitschr. 54, 215.

Groth u. Kaiser. Zeituchrift f. Krvatallogr. LV. 
114 H. E. Merwin. Die thermale Entwässerung des Stilbit u. Thaumasit; usw.

ist proportional dem Quotienten: Wasserverlust während der letzten Erhitzung durch Erhitzungsdauer. In den Fällen, wo die Kreise beträchtlich einander überdeckten, wurden sie ersetzt durch zwei fortlaufende Linien, die durch das Ende eines jeden auf der Kurve senkrecht stehenden Durchmessers gezogen wurden. Die Erhitzungsdauer betrug 5 Minuten.

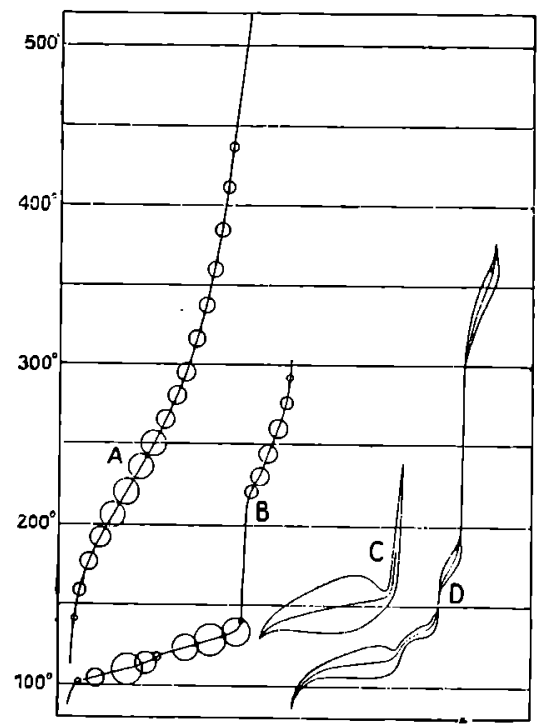

$\mathrm{CuSO}_{4} .5 \mathrm{H}_{2} \mathrm{O}$ ( $\mathrm{B}$ i. d. Fig.) verliert leicht zweimal je zwei Moleküle Wasser, dann ein Molekül bei einer weit höheren Temperatur. Bei $25^{\circ}$ beträgt der Dampfdruck, bei dem das Penta- und das Trihydrat nebeneinander existieren können, ungefähr $7 \mathrm{~mm}$ Quecksilber, für das Tri- und das Monohydrat ungefähr 4,7 mm und für das Monohydrat und das Anhydrid ungefähr $\left.0,8 \mathrm{~mm}^{1}\right)$.

Stilbit ( $A$ i. d. Fig.) gibt kontinuierlich Wasser ab ohne die geringste Andeutung einer Discontinuität. Bei Anwendung von zehn Minuten langen Erhitzungszeiten erhält man eine Kurve von dem nämlichen allgemeinen Verlauf, ein wenig unterhalb der eingetragenen. Der gesamte Glühverlust betrug $17,6 \%$.

$\mathrm{MgSO}_{4} .7 \mathrm{H}_{2} \mathrm{O}$ (D i. d. Fig.) zeigt vier deutliche Perioden, in denen eine maximale Entbindung von Wasser eintritt. Die letzten drei entsprechen je einem Molekül, die erste, während welcher vier Moleküle Wasser abgegeben wurden, dürfte die Zersetzung des Heptahydrates direkt zum Trihydrat anzeigen; müglicherweise bilden sich dazwischen intermediäre $\mathbf{H y -}$ drate, die sich aber sofort zersetzen. Derartige Hydrate, die alle ungefähr den gleichen Dampfdruck besitzen, sind bei tieferer Temperatur bekannt ${ }^{1}$ ). Das Di- und das Trihydrat sind meines Wissens bisher nicht bekannt gewesen. Die Temperaturintervalle waren $4^{\circ}$ unterhalb $157^{\circ}, 10^{\circ}$ zwischen $157^{\circ}$ und $212^{\circ}$, endlich $20^{\circ}$ über $212^{\circ}$.

Thaumasit, $\mathrm{CaSO}_{4} . \mathrm{CaCO}_{3} . \mathrm{CaSiO}_{9} .1 \mathrm{~s}_{2} \mathrm{O}(\mathrm{C}$ i. d. Fig.) verliert 14 Moleküle Wasser ganz ähnlich wie das Magnesiumsulfat seine ersten vier. Nur das letzte Molekül ist sehr viel fester gebunden. Die Temperaturintervalle waren $3^{\circ}$.

Geophysical Laboratory, Carnegie Institution of Washington, Oktober 1914.

1) H. W. Foote und S. R. Scholes, Journ. of the Americ. Chem. Soc. 1911, 33, 1324 . 